\title{
"PROTEÇÃO E SEGURANÇA PARA A POPULAÇÃO, MAS NÃO AO TODO": SENTIDOS E SIGNIFICADOS DA POLÍCIA MILTTAR E SUAS ATRIBUIÇÕES PARA ESTUDANTES DE PSICOLOGIA
}

"PROTECTION AND SECURITY FOR THE POPULATION, BUT NOT TO THE WHOLE": SENSES AND MEANINGS OF THE MILITARY POLICE AS ATTRIBUTED BY PSYCHOLOGY STUDENTS "PROTECCIÓN Y SEGURIDAD A LA POBLACIÓN, PERO NO AL CONJUNTO": SENTIDOS Y SIGNIFICADOS ACERCA DE LA POLICÍA MILITAR Y SUS ATRIBUCIONES A LOS ESTUDIANTES DE PSICOLOGÍA

Divino de Jesus da Silva Rodrigues* Ana Paula Soares da Silva

\begin{abstract}
RESUMO
A pesquisa objetivou apreender os sentidos e significados de estudantes universitários de Psicologia acerca da Polícia Militar e suas atribuições na sociedade. Alicerçou-se nos arcabouços teóricos da Psicologia sócio-histórica e no método do materialismo histórico dialético. A coleta foi realizada com dez universitários, entre 18 e 29 anos, do curso de Psicologia da Pontifícia Universidade Católica de Goiás, por meio de entrevista semiestruturada. A sistematização e a análise foram guiadas pela metodologia dos núcleos de significação. Os resultados apontam que os sentidos e significados que atribuem à Polícia Militar entrelaçam-se com as atividades que desempenham na sociedade. Assim, por um lado, apontam que a corporação tem como função trazer proteção e segurança para a população, mas, por outro, é significada como uma força autoritária, violenta, repressora e coercitiva, mantendo açóes diferenciadas de acordo com os interesses do Estado e de classes sociais.
\end{abstract}

Palavras-chave: Violência policial. Psicologia sócio-histórica. Universitários de Psicologia. Sentidos e significados.

\footnotetext{
"Professor na Pontifícia Universidade Católica de Goiás (PUC Goiás), atuando no Curso de Psicologia e nos Programas de PósGraduação Stricto Sensu em Educação (Escola de Formação de Professores e Humanidades) e Psicologia (Escola de Ciências Sociais e da Saúde).E-mail: psico.divino@gmail.com.

"* Professora livre-docente na Universidade de São Paulo (USP), atuando no Curso de Psicologia e no Programa de Pós-Graduação Stricto Sensu em Psicologia da Faculdade de Filosofia, Ciências e Letras de Ribeirão Preto (FFCLRP-USP). E-mail: apsoares. silva@usp.br.
} 


\begin{abstract}
This present research aimed to gather psychology faculty students' senses and meanings concerning the Military Police and their attributions in the society. It was based on the theoretical frameworks of sociohistorical Psychology and the method of dialectical historical materialism. Data were collected from ten university students, aged between 18 and 29 years old, from the Psychology course of the Pontifical Catholic University of Goiás, through semi-structured interviews. The systematization and the analysis were guided by the nuclei of meaning methodology. The results point out that the senses and significance attributed to the Military Police are intertwined with the activities they perform within the society. Thus, on one hand, they point out that the function of the corporation is to bring protection and security to the population, but, on the other hand, it is signified as an authoritarian, violent, repressive and coercive force, maintaining differentiated actions according to the interests of the state and social classes.
\end{abstract}

Keywords: Police violence. Sociohistorical Psychology. Psychology University students. Senses and meanings.

\title{
RESUMEN
}

La investigación tuvo como objetivo comprender los sentidosy los significados atribuidos a los estudiantes universitarios de Psicología acerca de la Policía Militar y sus atribuciones en la sociedad. Se basó en los marcos teóricos de la Psicología sociohistórica y en el método del materialismo histórico dialéctico. La colección se realizó con diez estudiantes universitarios, entre 18 y 29 años, del curso de Psicología de la Pontificia Universidad Católica de Goiás, a través de una entrevista semiestructurada. La sistematización y el análisis ocurridos fueron guiados por la metodología de los núcleos de significado. Los resultados indican que los significados y atributos atribuidos a la Policía Militar están entrelazados con las actividades que realizan en la sociedad. Por lo tanto, por un lado, señalan que la función de la corporación es brindar protección y seguridad a la población, pero, por otro lado, se representa como una fuerza autoritaria, violenta, represiva y coercitiva, manteniendo diferentes acciones de acuerdo con los intereses del estado y clases sociales.

Palabras clave: Violencia policial. Psicología sociohistórica. Estudiantes universitarios de Psicología. Sentidos y significados. 


\section{INTRODUÇÃO}

Constituição Federal de 1988, no artigo 144, parágrafo 5º estabelece que a Polícia Militar, entre os órgãos responsáveis pela segurança pública, 1 tem o dever pela atividade ostensiva e a preservação da ordem pública na sociedade. Ainda de acordo com esse artigo, parágrafo $6^{\circ}$, as corporaçóes militares brasileiras são forças auxiliares e reservas do Exército, subordinadas aos governos dos Estados, Distrito Federal e Territórios.

Segundo o Decreto no 88.777 , de 30 de setembro de 1983, que aprova o regulamento das polícias militares e corpo de bombeiros militares, o policiamento ostensivo é uma "ação policial, exclusiva das Polícias Militares, em cujo emprego o homem ou a fração de tropa engajados sejam identificados de relance, quer pela farda quer pelo equipamento, ou viatura, objetivando a manutenção da ordem pública"; sendo que esse policiamento "visa ilidir condutas ilícitas, protegendo a integridade de pessoas, bens e serviços" (Lazzarini, 1999, p. 103).

Em relação à preservação da ordem pública, esse regulamento descreve que "é o exercício dinâmico do poder de polícia, no campo da segurança pública, manifestado por atuações predominantemente ostensivas, visando a prevenir, dissuadir, coibir ou reprimir eventos que violem a ordem pública" (Decreto $n^{o}$ 88.777/,1983).

Porém, em relação aos limites das ações dos policiais militares, não existem critérios únicos que normatizam as condutas no exercício dessas atribuições (Bittner, 2003). O que existem são documentos nacionais legais e tratados internacionais que visam ao controle das ações realizadas pelas forças policiais do Brasil.

Nessa direção, entre os documentos nacionais, destacam-se o Decreto-Lei ${ }^{\circ}$ 2.848, de 7 de dezembro de 1940; a Lei no 4.898, de 9 de dezembro de 1965; a Constituição Federal de 1988; e a Lei no 9.455, de 7 de abril de 1997, que apontam as garantias de direito à vida, dignidade, cidadania e integridade física, entre outros direitos fundamentais para todos os cidadãos. Esses documentos legais proíbem o abuso de poder e de autoridade, prisóes arbitrárias e torturas.

Já entre os tratados internacionais, ressaltam-se: a Declaração Universal dos Direitos do Homem; o Código de Conduta para os Encarregados da Aplicação da Lei; o Conjunto de Princípios para a Proteção de todas as Pessoas Sujeitas a Qualquer Forma de Detenção ou Prisão; o Princípios Relativos a uma Eficaz Prevenção e Investigação de Execuções Extralegais, Arbitrárias e Sumárias; Princípios Básicos sobre a Utilização da Força e de Armas de Fogo pelos 
Funcionários Responsáveis pela Aplicação da Lei. Esses são tratados aprovados pela Organização das Nações Unidas e de todos os quais o Brasil é signatário, que determinam a proibição de tratamentos cruéis, desumanos ou degradantes e buscam, assim, a garantia de direitos fundamentais inerentes à pessoa humana (Rodrigues \& Sousa, 2017).

Apesar desses marcos legais, dados do Anuário Brasileiro de Segurança Pública (Fórum Brasileiro de Segurança Pública, 2018) apontam que, no ano de 2017, foram mortas 14 pessoas por dia decorrentes de intervençôes policiais no Brasil. Mesmo com esse número elevado, o relatório da Anistia Internacional (2018) alerta que "Os dados sobre pessoas mortas pela polícia continuaram imprecisos, pois os estados mantêm registros precários e utilizam metodologias diferentes" (p. 90). Nesse contexto, são as populações mais empobrecidas as que sofrem as arbitrariedades da polícia. Segundo do relatório da Anistia Internacional (2018), "as operaçôes policiais em favelas e áreas marginalizadas geralmente resultaram em tiroteios intensos e mortes" (p. 90).

Como já apontaram Rodrigues e Sousa (2017), dado o caráter universal dos documentos nacionais e internacionais, eles não garantem uma proteção singular na defesa de todos os cidadãos da sociedade. As especificidades e as particularidades de grupos socioeconômicos, etários, de mulheres e étnicoraciais, por exemplo, demandaram a criação de uma sistemática especial como reconhecimento de que há profundas desigualdades que o sistema geral de proteção dos direitos humanos não consegue abarcar. Como pontua Foucault (2014, p. 270), "Seria hipocrisia ou ingenuidade acreditar que a lei é feita para todo mundo em nome de todo mundo; que é mais prudente reconhecer que ela é feita por alguns e se aplica a outros". Contudo é necessário ressaltar que, apesar dessas questôes que atravessam a materialidade desses documentos nacionais e tratados internacionais como garantia de direitos a todos os cidadãos na sociedade, eles constituem-se em mecanismos legais usados pela sociedade civil organizada que alicerçam a luta contra ações arbitrárias cometidas por agentes do Estado, incluindo a Polícia Militar.

Em junho de 2017, no contexto das manifestaçóes que ocorreram contra as propostas de mudanças nos direitos previdenciários e trabalhistas que estavam em discussão no Congresso Nacional, a repressão policial e a atuação arbitrária dos policiais militares foram destaque na imprensa nacional, momento em que muitos estudantes universitários foram inclusive presos. Esse fato gerou indagações sobre a percepção de estudantes acerca da atuação da Polícia Militar e passou a compor o conjunto de estudos sobre as diversas tipificaçôes de violência investigadas pela linha de pesquisa "Estudos da violência contra crianças, adolescentes, jovens e mulheres", do grupo de pesquisa "Infância, família e sociedade". Dessa maneira, 
elaborou-se a investigação denominada "Sentidos e significados da violência policial para estudantes universitários (2017-2025)", que vem coletando dados com estudantes dos cursos universitários, tanto da Pontifícia Universidade Católica de Goiás (PUC Goiás) quanto em outras universidades no Município de Goiânia. O estudo foi aprovado pelo Comitê de Ética em Pesquisa da PUC Goiás, sob o parecer no 2.157.058, CAEE: 69339517.2.0000.0037.

$\mathrm{O}$ artigo explora o material produzido com estudantes universitários do curso de Psicologia. Conhecer o que os estudantes de nossa área pensam sobre o assunto é trazer o debate das ações da polícia para o interior dos processos formativos em Psicologia, considerando que eles estão sendo introduzidos em uma profissão que atua em instituições e problemáticas correlacionadas ao tema e que tem, como o primeiro princípio de seu Código de Ética Profissional, o respeito e a promoção "da liberdade, da dignidade, da igualdade e da integridade do ser humano, apoiado nos valores que embasam a Declaração Universal dos Direitos Humanos" (Conselho Federal de Psicologia, 2005).

É importante destacar que o estudo com os estudantes de Psicologia inseriuse no projeto "Identidade e vulnerabilidade humana em contextos da Região Centro-Oeste do Brasil", do Programa Nacional de Cooperação Acadêmica da Coordenação de Aperfeiçoamento de Pessoal de Nível Superior (CAPES Procad, Edital no 071/2013), e foi desenvolvido durante o estágio de pós-doutorado do primeiro autor deste artigo, realizado no Departamento de Psicologia (Faculdade de Filosofia, Ciências e Letras de Ribeirão Preto, Universidade de São Paulo FFCLRP-USP).

\section{MÉTODO}

Este estudo é de caráter qualitativo e alicerçou-se nos pressupostos teóricos da Psicologia sócio-histórica de base vigotskiana e no método do materialismo histórico dialético. Nessa perspectiva, a palavra, considerando os sentidos e significados que nela se constroem, é a unidade de análise para a compreensão das vivências e experiências do sujeito. Para o autor, a palavra é "a expressão mais direta da natureza histórica da consciência humana" (Vigotski, 2009, p. 486).

A partir das investigações realizadas por Paulham (1856-1931), Vigotski (2009) entende que os sentidos de uma palavra são uma formação "dinâmica, fluida, complexa, que tem várias zonas de estabilidade variada. O significado e apenas uma dessas zonas do sentido que a palavra adquire no contexto de algum discurso e, ademais, uma zona mais estável, uniforme e exata" (p. 465). $\mathrm{O}$ autor afirma ainda: "Como se sabe, em contextos diferentes, a palavra 
muda facilmente de sentido. O significado, ao contrário, é um ponto imóvel e imutável que permanece estável em todas as mudanças de sentido da palavra em diferentes contextos" (Vigotski, 2009, p. 465). E completa o autor que "O sentido real de cada palavra é determinado, no fim das contas, por toda a riqueza dos momentos existentes na consciência e relacionados aquilo que esta expressa por uma determinada palavra” (p. 466).

Para a produção do material empírico, utilizou-se a entrevista semiestruturada. As entrevistas duraram aproximadamente 50 minutos e foram realizadas em local reservado da PUC Goiás.

A sistematização e análise dos dados ocorreram por meio do procedimento analítico qualitativo "núcleos de significação", proposto por Aguiar, Soares, e Machado (2015), sendo o suporte para desvelar as contradições expressas nas falas dos estudantes, entrelaçadas na universalidade, particularidade e singularidade do fenômeno investigado, na busca de apreender a essência para além da aparência dos relatos dos estudantes.

\section{PARTICIPANTES}

Participaram do estudo dez estudantes universitários do Curso de Psicologia da PUC Goiás (um de cada semestre), inclusos na pesquisa com base nos seguintes critérios: ter entre 18 anos a 29 anos; estar regularmente matriculado e frequentar o curso; consentir participar da pesquisa, por meio da assinatura do Termo de Consentimento Livre e Esclarecido (TCLE). Os critérios de exclusão foram: ser ou ter sido integrante de uma corporação policial; ter parentesco em qualquer grau com integrantes de uma corporação policial; ter relacionamento afetivo com algum integrante de forças policiais.

Os nomes dos estudantes universitários são fictícios, sendo eles:

Ana, 23 anos, solteira, parda, não trabalha, família constituída por mais duas pessoas, renda per capita de $\mathrm{R} \$ 2.660,00$.

Beatriz, 21 anos, solteira, branca, não trabalha, família constituída por mais duas pessoas, renda per capita de $\mathrm{R} \$ 3.330,00$.

Carlos, 19 anos, solteiro, branco, tem bolsa parcial de estudo, não trabalha, família constituída por mais três pessoas, não informou renda per capita.

Ester, 18 anos, solteira, branca, não trabalha, família constituída por mais três pessoas, renda per capita de $\mathrm{R} \$ 4.500,00$.

Joana, 20 anos, solteira, parda, não trabalha, família constituída por mais três pessoas, renda per capita de R \$3.750,00. 
João, 28 anos, solteiro, branco, tem bolsa total de estudo, trabalha, família constituída por mais três pessoas, renda per capita de $\mathrm{R} \$ 1.250,00$.

Maria, 24 anos, solteira, branca, tem bolsa parcial de estudo, não trabalha, família constituída por mais cinco pessoas, renda per capita de $\mathrm{R} \$ 416,00$.

Patrícia, 19 anos, solteira, branca, não trabalha, família constituída por mais duas pessoas, renda per capita de $\mathrm{R} \$ 3.660,00$.

Paulo, 20 anos, solteiro, negro, tem bolsa parcial de estudo, trabalha, família constituída por mais três pessoas, renda per capita de $\mathrm{R} \$ 875,00$.

Sílvia, 22 anos, casada, branca, tem bolsa total de estudo, trabalha, família constituída por mais duas pessoas, renda per capita de $\mathrm{R} \$ 443,00$.

\section{RESULTADOS E DISCUSSÃO}

\section{1. "Proteger mesmo, é proteger"}

Sentidos relativos à Polícia Militar apareceram nas falas dos participantes atrelados à gestão e à responsabilidade da garantia da segurança e proteção dos cidadãos, tal como expressam: Ester ("Decide a segurança da cidade", tem a "função de proteger, eu acho, de trazer a segurança, trazer segurança para a população"); João ("Deveria nos proporcionar segurança, proteger toda a população", "É de manter a ordem e segurança também”); Patrícia ("Proteger mesmo, é proteger"; "O policiamento, a gente se sente mais seguro, porque tem essa insegurança mesmo. Lá no setor onde eu morava, não podia sair sete horas assim"); Maria ("Ela veio para proteger a sociedade, para guardar a sociedade"; "Ensinar a sociedade a se proteger, porque, muitas vezes, a gente, nunca a gente não vai ter um policial vinte e quatro horas, nem nos guardando, nem seria guarda costa, segurança particular, mas acredito que a polícia, que o papel dela é proteger a sociedade, ensinar a sociedade a se proteger e faz o papel dela"); Sílvia ("Seriam as pessoas que deveriam cuidar da integridade das outras pessoas. Da integridade física das outras pessoas"); Ana ("A figura que remete a mim é segurança, quando eu preciso de alguma proteção tudo mais, a figura que eu vejo é a Polícia Militar"); Beatriz ("O papel deveria de ser de proteger, né, os cidadãos e tal"); Carlos ("Eu compreendo que o papel dela é a de defesa").

Por sua vez, a estudante Joana adiciona outro sentido, a atuação na organização social, de modo a manter as relações harmônicas, e traz, em sua fala, como exaluna de colégio militar, a voz da instituição policial: 
Então, é meio complicado dizer isso, eu tenho certa responsabilidade porque eu estudei em colégio militar. Então, é o que eles sempre falavam lá, é a questão que a Polícia Militar tem a obrigação, melhor dizendo assim, de organizar a sociedade, então eles falavam muito de cidadania. O tanto que quando fala de Polícia Militar, a primeira palavra que me vem na cabeça é cidadania. [. . . . Cidadania, eu acho que é para a gente viver, assim, em harmonia, de forma com que a gente consiga se organizar de uma forma saudável, assim, de modo bem geral.

\section{2. "Proteção e segurança, mas não ao todo"}

Os sentidos de proteção e segurança, contudo, foram trazidos por meio do diálogo entre o que seria idealmente a função da polícia e o que, para os estudantes, é a condição real de suas atividades. A discrepância entre a expectativa de atuação da polícia e o que ocorre de fato é explicada por diferentes perspectivas.

Para Maria, isso se dá em virtude de uma postura pouco ativa ou comprometida da polícia, o que afeta seu o sentimento de segurança e proteção pessoal:

Que deveria ser órgão que defende a população, defende a sociedade, que defende os direitos, nem? Os direitos dos estudantes, por exemplo: aqui na Praça Universitária, direto tem assalto. Todos os dias, você escuta alguém falando de assalto no Setor Universitário. Nestes dias, teve um caso no ponto de ônibus, que esfaqueou uma menina para roubar o celular. Onde está a polícia? Nem? Então assim, o papel da polícia seria defender a sociedade, mas atualmente o que a gente vê é que não é isso que acontece, nem. A gente passa pelas viaturas, eles estão sentados, olhando o tempo, não estão vigiando, não estão fazendo ronda nem estão é. Estacionado o carro embaixo de uma árvore, vai ficar lá de boa, tranquilo, nem. Às vezes você nem vê viatura. É quando a gente está à mercê, a mercê dos bandidos na verdade. Acredito que nossa casa já virou a prisão, e os bandidos estão soltos, porque a gente não pode sair mais na rua, nem sai com tranquilidade. Eu mesmo, quando saio da PUC, vou para um algum lugar, eu fico olhando, alerta, ligo meu estado de alerta 360 graus para ver o que está acontecendo.

Paulo, por sua vez, introduz um olhar diferenciado para as classes sociais como elemento presente na atuação desigual e seletiva da política: "Querendo ou não, é uma forma que a gente tem de se sentir resguardado quando corre risco de assalto ou algo assim, então assim acho que esse é o papel para a sociedade”. "Acho que a polícia é uma instituição, que ela está aí, supostamente ela foi criada para servir e proteger." Em seguida, o estudante frisa: "Aliás, ela foi realmente criada para servir e proteger. Foi criada para servir e proteger os interesses do Estado e dos grandes empresários. A última função dela é servir proteger a gente aqui mais de baixo. Acho que é isso". "O papel principal dela é servir os interesses da elite e, nas horas vagas, ela desempenha o papel ali de um controle [. . .] da criminalidade." 
Uma terceira perspectiva aprece na entrevista de Carlos, que apresenta uma postura crítica do papel da polícia como um aparelho do Estado. É nessa perspectiva que aparecem as relações da polícia com as manifestações públicas contrárias às ações do governo e o seu uso por interesses daqueles que detêm o poder de direção política da sociedade:

Eu compreendo ela de duas formas. Primeiro, eu compreendo que o papel dela é a de defesa, né? De garantir os direitos que todos têm. Assim, os direitos básicos, né? Segurança e tal. Mas, na real, eu acho que não é isso que ela faz. Eu acho que acontece que o governo usa dela como uma forma de mostrar a autoridade que ele tem, e assim ele pode, digamos que, conter as pessoas que não estariam satisfeitas de alguma forma. Por exemplo, nas manifestaçōes, né? Quando a polícia é acionada e acaba agredindo as pessoas que estão nas manifestações. Então eu acho que, na teoria, é uma coisa muito linda, Polícia Militar, você se sente seguro e tal, e eu acho que na verdade não é. Na prática, não é isso, bem isso. Eu acho que isso acontece, assim, são vários motivos. Mas eu acho que, quando você tem um direito e você vê esse direito sendo retirado de você, e você quer lutar por aquilo. Aí a forma de você lutar é impondo o que você pensa e trazendo também as pessoas para isso, para esse movimento. Você acaba que torna um perigo, né? Um perigo para quem não quer, para quem não quer que isso aconteça. Para quem quer se manter onde está. Então, é, acontece que, eles precisam desse tipo de força, desse tipo de autoridade para conter isso. [. . .] E até mesmo quando nós vamos nos manifestar por eles, se elas dessem o apoio de garantir a ordem do movimento, garantir a organização, mas não, elas agridem as pessoas e acaba que a polícia não vê isso como agressivo ou violento.

\section{Esses sentidos trazidos por Carlos estão também presentes na fala de Patrícia:}

Bom, assim, a gente tem visto assim, como proteger a sociedade, não sei te explicar direito, mas, não assim, não totalmente assim. Esses protestos que os estudantes fazem, aconteceram aquelas coisas, assim, a violência que eles fizeram com os estudantes. Não sei te explicar direito. Segurança, mas não ao todo assim. Bom, por essa visão mesmo que eu vejo, entende? Da sociedade em meio assim, as pessoas tentam mudar sabe? As leis, essas coisas, mas a Polícia não dá segurança para todos.

\section{3. "Eu acho que eles excedem"}

Outro conjunto de significações aparece associado aos abusos cometidos pela polícia. A estudante Sílvia, apesar de reconhecer a importância da função da polícia para a proteção e segurança, destaca:

Contudo, eu acho que eles excedem. Para falar bem a verdade, acho que eles excedem, às vezes, no que é a função deles. Eu acho que eles fazem coisas que não precisam, abordagens, blitz, violentas [.. . ] A Polícia Militar deveria atuar com essas pessoas que cometeram esses crimes pequenos, dessa forma. Seria isso, proteger a sociedade dessas pessoas que estão com essa dificuldade de viver bem na sociedade, de viver de forma digna, alguma coisa nesse sentido. Sem violência. 
A estudante Ana menciona o sentimento de medo que o excesso na atuação da polícia gera: "A figura dos policiais deveria ser de uma figura de segurança, que é a gente poderia andar na rua, porque sabe que tem a Polícia Militar que está ali com a gente. Deveria ser este o papel”. Contudo a estudante acrescenta:

Em alguns momentos, eu vejo que o papel que eles colocam em nosso meio é um papel de medo. As pessoas têm medo de ser abordadas, porque, igual eu falei, tem pessoas que, ao serem abordadas, tem a questão da violência, eles agridem, eles batem. Em outras pessoas, isso não acontece, mas eu não sei o critério utilizado.

Para Carlos, é a repressão e a coação que mais se pronunciam na atuação excessiva e discriminadora da Polícia Militar, em especial quando se trata de pequenos infratores:

Para mim, o que eu vejo é que o papel dela é de repreender, de coagir. Ela coage através da violência que ela é treinada a fazer. As pessoas que tentam, de certa forma, questionar o que elas (polícias) vejam que seja errado, na concepção delas, eles tentam coagir isso de forma violenta. $E$ isso é feito porque alguém as treinou para isso com um propósito, isso é o propósito que elas teriam. Claro que elas, às vezes acontece o que eu estava falando, o garoto estava fumando um beck, e elas vão lá e tiram, vão lá e batem nele. Elas estão vendo uma pessoa ser assaltada, muitas vezes, um exemplo, elas vão e impedem. Não que isso aconteça com frequência, mas então elas fazem isso também. Que seria, na teoria, o que elas deveriam fazer também, defender o direito à segurança, mas, na verdade, elas fazem isso de maneira muito violenta. É até muito violenta com as pessoas que infringem as leis. Por exemplo, você vê muito isso quando os policiais pegam aqueles pequenos infratores e batem muito neles, às vezes chegam até a matar. Na teoria, seria lindo, né, se eles realmente defendessem nossos direitos.

\section{4. "Estado não fornece condições para ele trabalhar"}

Maria, que, como mencionado, foi estudante de colégio militar, é única que traz a crítica à forma como a política de segurança é feita pelo Estado no que se refere à corporação dos policiais militares:

Esse papel, tenho minhas dúvidas. Olha, a gente tem que olhar por vários ângulos. Primeiro, eu entendo o lado do policial, só que ele foi contratado para esse serviço, mas o que a gente vê nas notícias atualmente é que o Estado não fornece condições para ele trabalhar, nem eu estou aqui culpando muitos policiais, mas acaba que isso é tudo um sistema, sistema de governo [. . . ] Por exemplo, aqui no Estado, não tem feito concurso, então os policiais estão aposentando. Aposentando, só vai reduzindo ao longo dos anos. Ao longo dos anos, se a gente for olhar, só tem sido reduzido. E também munição, armas, coisas para trabalhar, e os bandidos estão mais bem armados e munidos que a própria polícia. Então a polícia não está bem preparada para trabalhar. Claro que tem esse lado que o Poder Público, de poder auxiliar sustentar e fundamentar esses policiais para o trabalho, mas também tem o lado dos 
policiais, de trabalhar, cumprir com seu papel de trabalho, nem. Mas também uma coisa que eu vejo na polícia é que os policiais estão adoecidos, porque essa sociedade altamente violenta, altamente corrupta, os policiais não são cuidados psicologicamente, falando mesmo de médicos, tanto policiais afastados, que tem tantos policiais aposentados com problemas psiquiátricos que lidam diariamente com as violências e eles não estão sendo cuidado para lidar com essa violência também, muitas vezes a forma deles é enfrentar essa violência é com mais violência, né, com as abordagens violentas. Em casa, com quantas famílias de policiais a gente vê aí; esses dias, um tempo desses na televisão, passou o policial que agrediu a esposa e matou o filho. Acaba que a pessoa vai ficando num nível de adoecimento tão grande que descontar em outras pessoas, e isso vai combinar lá na abordagem, no dia do trabalho dele. Acredito que os policiais precisam ter um apoio do Poder Público e um apoio da saúde, da sociedade acho que tudo para eles trabalharem e cumprir o papel deles, e a gente cobra o papel dele, sendo que a gente não dá suporte para ele trabalhar.

A estudante Beatriz, por sua vez, menciona a relação complexa de trabalho dos policiais: "Não sei! Sei que é aquele tabu, né, da gente não acreditar, de não confiar muito na polícia. Mas assim, tem alguns que são bons mesmo, que fazem o trabalho, só que tem outros que não fazem”. Nessa direção, a estudante Beatriz afirma:

Eles também, como cidadãos, né, que fossem exemplos, eu acho. Não sei se é bem isso. Mas é fazer o trabalho deles como todo mundo deveria fazer. Lógico que o trabalho dele (policial) é mais estressante. É um trabalho mais complicado, então eu entendo dessa forma.

\section{DISCUSSÃO}

Pelas falas dos estudantes, constata-se que os sentidos e significados que atribuem à Polícia Militar pontuam que a corporação é responsável pela "segurança da cidade; organizar a sociedade; proteger a população; garantir direitos; cuidar da integridade física das pessoas". Sobre suas atribuições, apontam que a Polícia Militar tem a função de "trazer proteção e segurança para a população", evidenciam que a corporação, como figura da segurança, tem o dever de manter a ordem, defender a população com instruções de educação contra a criminalidade.

Nas falas de alguns estudantes, reverberou o discurso da atuação contra os "bandidos", o que acarreta numa relação de insegurança quando da ausência de policiamento mais ostensivo nas ruas e nos bairros.

Essas narrativas expressas são repetidas incessantemente na sociedade. Dessa maneira, propostas de ações de endurecimento contra infratores são defendidas como efetivas e resolutivas no combate à criminalidade, sendo amplamente divulgadas por uma parte da mídia e utilizadas como plataforma política e eleitoral. Segundo Rocha (2013, p. 89), 
A sensação de insegurança faz com que a população exija mais polícias nas ruas. Pouco importa os indicadores. Para aplacar isso, as estratégias clássicas adotadas têm sido recrudescimento penal, encarceramento em massa e policiamento repressivo.

Rodrigues e Sousa (2017, p. 193) chamam a atenção para o fato de que essas demandas "ocultam a proteção da segurança pública a uma pequena parcela de pessoas na sociedade, e uma grande maioria não recebe esta proteção".

Sobre a atuação discriminadora e desigual da polícia, que aparece nas falas dos participantes, é necessário destacar que o manto das leis não é extensivo a toda a população, uma vez que a proteção e a segurança são garantidas aos cidadãos que têm acesso aos direitos do Estado democrático. Nesse aspecto, as falas articulam a desigualdade à atuação de um Estado que defende interesses de empresários e da elite na sociedade, utilizando a corporação na força coercitiva, muitas vezes autoritária, violenta e repressora, em especial em relação a grupos vulneráveis e pequenos infratores. Dessa forma, as falas tocam na relação entre a atuação da polícia e os efeitos da desigualdade social da nossa sociedade que, de acordo com Sawaia e Silva (2019, p. 37), no cotidiano e no funcionamento das instituições se "aloja nas relações preconceituosas, nas violências de toda ordem. Enfim, em todas as formas de ser tratado como uma pessoa sem importância (invisibilidade social)".

Os relatos evidenciam ainda que agentes da corporação, no exercício de suas funções, geram medo e desconfiança, principalmente em ações de abordagens e blitz, contrariando ainda seu papel de garantia do direito de expressão da cidadania e das diferentes formas de lutas e manifestações democráticas.

Esses relatos dos estudantes corroboram as afirmações de Martins (2017) em relação às intervenções das forças policiais em manifestações que são

Extremamente violenta no seu trabalho de manutenção da ordem pública, principalmente quando tem que tratar com os movimentos sociais [. . .], fundamentalmente a militar, quando entra nas [.. .] manifestações democráticas de trabalhadores e trabalhadoras no espaço público, quase sempre age de forma violenta e desproporcional (p. 99).

As ações arbitrárias praticadas pela Polícia Militar, contudo, não ocorrem de formas isoladas ou eventuais. Estão inseridas em um contexto mais amplo do modelo da estrutura e da cultura organizacional da Polícia Militar, que mantém em sua concepção o policiamento ostensivo, desde sua criação, conforme afirma Bicudo (2000):

O Congresso Constitucional, eleito em 1986, não soube inovar e institucionalizou as corporações militares dos estados como um dos organismos responsáveis pelo policiamento 
preventivo; e fez mais, pois manteve um sistema judiciário corporativo, responsável, em larga medida, pela impunidade que ainda acoroçoa a violência que deles emana na sua atuação enquanto polícia ostensiva (pp. 97-98).

Assim, foi preservado o modelo histórico da corporação na defesa do Estado em detrimento dos direitos individuais e coletivos dos cidadãos, apresentando enormes transgressões aos direitos humanos dos cidadãos (Lima, Bueno, \& Mingardi, 2016).

As arbitrariedades raramente são investigadas e julgadas. "Os responsáveis dificilmente são levados à Justiça, e a grande maioria das vítimas não obtém nenhuma reparação. Essa impunidade alimenta o ciclo de violência que marca as operações policiais no país" (Anistia Internacional, 2015, p. 11). Além do mais, sobre essa questão, aponta Bittner (2003, p. 129): "É extremamente raro que as ações policiais envolvendo o uso da força sejam realmente revistas e julgadas por alguma outra pessoa qualquer".

Sobre o adoecimento dos policiais que reverberou nos relatos de uma estudante, justificado por falta de apoio do Poder Público em relação tanto às condições infraestruturais de trabalho quanto de assistência à saúde, a fala atenta para o sofrimento físico, mental e mortes. Segundo Minayo, Assis, e Oliveira (2011):

De modo geral, o sofrimento físico e mental é resultante do conjunto de situaçóes vivenciadas no cotidiano do trabalho. Nesse contexto, identificamos fatores que associam problemas de condições e organização ocupacional - entre eles, escasso treinamento e falta de planejamento das atividades - com excessiva jornada de trabalho, pouco tempo para descanso e lazer, precárias condiçôes materiais e técnicas e baixos salários (p. 2206).

Dados do Anuário Brasileiro de Segurança Pública (Fórum Brasileiro de Segurança Pública, 2018) apontam que, no ano de 2017, foi morto um policial militar ou civil por dia, cenário também inaceitável. Nessa direção, afirmam Souza e Oliveira (2017): "A realidade dos policiais brasileiros é cruel e desumana, pois estes morrem, ficam feridos e são abandonados pelo Estado e por aqueles que os fizeram acreditar que eram invencíveis" (p. 26). As maiores vítimas na corporação da Polícia Militar são "os soldados, os cabos, os sargentos e os subtenentes [. . . ]. São estes que estão morrendo" (Souza \& Oliveira, 2017, p. 27). 


\section{CONSIDERAÇÕES FINAIS}

Os sentidos e significados dos estudantes de Psicologia à Polícia Militar e suas atribuiçõos desvelam as contradições sobre essa corporação e suas funções que estão presentes na sociedade: por um lado, estudantes reconhecem seu papel na garantia da segurança e falam a favor de um policiamento mais ostensivo e repressivo; por outro, apontam que as ações da Polícia Militar deveriam ser voltadas para a defesa dos direitos humanos a todos os cidadãos e denunciam as arbitrariedades e a ação desigual da polícia, na defesa da elite e, ou, dos que detêm o governo político da sociedade.

O conjunto dos relatos dos estudantes descortina a urgência na discussão sobre a estrutura organizacional e a concepção de policiamento público da Polícia Militar, uma vez que "Ainda se impõe um silêncio obsequioso frente ao problema da segurança pública, que nos desafia a pensar em um projeto de reforma das polícias que as valorizem como uma instituição central do Estado democrático de direito e da cidadania" (Lima et al., 2016, p. 67), visto "que os efeitos do regime militar ainda estão presentes no funcionamento dessas instituições" (Zaluar, 2007, p. 40). Não alterando sua estrutura e organização, que continuam nos moldes do Estado de exceção, e essa atuação é percebida pela população, o que aparece na fala dos estudantes de Psicologia, na mesma direção de Zaluar (2007), Soares (2014) afirma: "A herança da ditadura está relacionada à intocabilidade das polícias militares, às milícias, à tortura como método corrente, às execuções extraoficiais e ao tratamento seletivo dispensado aos cidadãos, a depender da [. . . ] sua situação socioeconômica” (p. 12).

Esse cenário explicita a profunda desigualdade social que existe em nosso país, que, segundo Sawaia (2009, p. 369), "Cerceia a experiência, a mobilidade, a vontade e impõe diferentes formas de humilhação".

Nessa direção, concorda-se com Lima et al. (2016), para esses autores, "Falta-nos um projeto de governança das polícias brasileiras e de alinhamento das políticas de segurança pública aos requisitos da democracia e à garantia de direitos humanos" (p. 50). Uma vez que se parte do prisma que a função primordial da Polícia Militar é garantir a cidadania (que, segundo uma das estudantes, foi o que mais ouviu sobre o papel da polícia quando estudou em uma escola militar), esse posicionamento exige a defesa intransigente da proteção dos direitos humanos para todos na sociedade, já que "o descumprimento desse requisito afeta diretamente no modo como a polícia é vista pela sociedade e, consequentemente, como ela desempenha suas funções" (Honório \& Silva, 2018, p. 2). 
Assim, é inaceitável mortes tanto da população civil quanto de policiais militares, ocorridas em ações arbitrárias realizadas pela Polícia Militar, o que desafia o estabelecimento do Estado Democrático de Direito e da construção de uma política pública de segurança cidadã.

Esse debate necessita envolver demais políticas públicas, entre as quais educação, cultura, esportes, trabalho, saúde, uma vez que não se pode debater segurança dissociada dessas políticas. Também o debate sobre a estrutura e organização da Polícia Militar necessita envolver, além do comando das forças policiais militares, todos os cidadãos da sociedade, principalmente a sociedade civil organizada e o Ministério Público.

Por fim, ressalta-se que esta pesquisa quer reafirmar o compromisso da Psicologia sócio-histórica com uma leitura crítica da sociedade pela Psicologia e o seu engajamento com os desafios que a realidade contemporânea nos apresenta, entre os quais questóes relativas à política de segurança pública. 


\section{REFERENCIAS}

Aguiar, W. M. J. Soares, R. S., \& Machado, V. C. (2015). Núcleos de significação: uma proposta histórico-dialética de apreensão das significações. Cadernos de Pesquisa, 45(155), 56-75.

Anistia Internacional (2015). Você matou meu filho: homicídios pela polícia militar na cidade do Rio de Janeiro. Rio de Janeiro: Anistia Internacional.

Anistia Internacional. (2018). Informe 2017-2018: o estado dos direitos humanos no mundo. Londres: Amnesty International.

Bicudo, H. (2000). A unificação das polícias. Estudos Avançados, 14(40), 91106.

Bittner, E. (2003). Aspectos do trabalho policial. São Paulo: Editora da Universidade de São Paulo.

Conselho Federal de Psicologia. (2005, agosto). Código de ética profissional do psicólogo: $13^{\circ}$ Plenário do Conselho Federal de Psicologia. Brasília: CFP. Recuperado a partir de https://site.cfp.org.br/wp-content/uploads/2012/07/ codigo-de-etica-psicologia.pdf

Constituição da República Federativa do Brasil de 1988. (1988). Brasília: Portal da Legislação. Recuperado a partir de http://www.planalto.gov.br/ccivil_03/ Constituicao/Constituicao.htm

Decreto-Lei $\mathrm{n}^{\circ}$ 2.848, de 7 de dezembro de 1940. (1940, 7 de dezembro). Código Penal. Brasília: Portal da Legislação. Recuperado a partir de http:// www.planalto.gov.br/ccivil_03/decreto-lei/del2848.htm

Decreto no 88.777, de 30 de setembro de 1983. (1983, 30 de setembro). Aprova o regulamento para as policias militares e corpos de bombeiros militares (R200). Brasília: Portal da Legislação. Recuperado a partir de http://www. planalto.gov.br/ccivil_03/decreto/D88777compilado.htm

Fórum Brasileiro de Segurança Pública. (2018). 12ª anuário brasileiro de segurança pública. São Paulo: Fórum Brasileiro de Segurança Pública. Recuperado a partir de http://www.forumseguranca.org.br/publicacoes/anuario-brasileirode-seguranca-publica-2018/

Foucault, M. (2014). Vigiar e punir: nascimento da prisão. (42a ed.). Petrópolis: Vozes. 
Honório, C. A., \& Silva, G. S. (2018). Direitos humanos e polícia militar: percepções e significados para os policiais militares do $17^{\circ} \mathrm{BPM}$ na cidade de Águas Lindas-Goiás. Rebesp, 11(1), 1-9.

Lazzarini, L. (1999). Estudos de Direito Administrativo. (2a ed.). São Paulo: Revista dos Tribunais.

Lei no 4.898, de 9 de dezembro de 1965. (1965, 9 de dezembro). Regula o Direito de Representação e o processo de Responsabilidade Administrativa Civil e Penal, nos casos de abuso de autoridade. Brasília: Portal da Legislação. Recuperado a partir de http://www.planalto.gov.br/ccivil_03/leis/14898.htm.

Lei no 9.455, de 7 de abril de 1997. (1997, 7 de abril). Define os crimes de tortura e dá outras providências. Brasília: Portal da Legislação. Recuperado a partir de http://www.planalto.gov.br/ccivil_03/leis/L9455.htm.

Lima, R. S., Bueno, S., \& Mingardi, G. (2016). Estado, polícias e segurança pública no Brasil. Revista Direito, GV, 12(1), 49-85.

Martins, J. G. A. (2017). Violência policial no Brasil: reflexões teóricas sobre a força policial como instrumento de repressão burguesa. Hegemonia - Revista Eletrônica do Programa de Mestrado em Direitos Humanos, Cidadania e Violêncial Ciência Política do Centro Universitário Unieuro, 22(num. esp.), 98-126.

Minayo, M. C. S., Assis, S. G., \& Oliveira, R. V. C. (2011). Impacto das atividades profissionais na saúde física e mental dos policiais civis e militares do Rio de Janeiro (RJ, Brasil). Ciência \& Saúde Coletiva, 16(4), 2199-2209.

Rocha, A. P. (2013). Polícia, violência e cidadania: o desafio de se construir uma polícia cidadã. Revista Brasileira de Segurança Pública, 7(1), 84-100.

Rodrigues, D. J. S., \& Sousa, S. M. G. (2017). Violência policial: sentidos e significados atribuídos por jovens da cidade de Goiânia. Psicologia em Estudo (online), 22, 187-198.

Sawaia, B. (2009). Psicologia e desigualdade social: uma reflexão sobre liberdade e transformação social. Psicologia \& Sociedade, 21(3), 364-372.

Sawaia, B. B., \& Silva, D. N. H. (2019). A subjetividade revolucionária: questões psicossociais em contexto de desigualdade social. In G. Toassa, T. M. C. Souza, \& D. J. S. Rodrigues (Org.), Psicologia sócio-histórica e desigualdade social: do pensamento à práxis. (pp. 20-41). Goiânia: Imprensa Universitária. 
Soares, L. E. (2014, 19-25 maio). Contra a violência, a favor da democracia. Jornal da USP.

Souza, E. L., \& Oliveira, M. R. (2017). Desconstruindo mitos: uma leitura de uma morte anunciada. In R. S. Lima, \& S. Bueno (Org.), $11^{\circ}$ Anuário Brasileiro de Segurança Pública. (pp. 26-39). São Paulo: Fórum Brasileiro de Segurança Pública.

Vigotski, L. S. (2009). A construção do pensamento e da linguagem. (2a ed.). São Paulo: Martins Fontes.

Zaluar, A. (2007). Democratização inacabada: fracasso da segurança pública. Estudos Avançados, 21(61), 31-49. 